\title{
Peri-implant diseases: The etiology, clinical features, diagnosis and treatment
}

\author{
T. K. Pal ${ }^{1}$, Goutam Das ${ }^{2, *}$ \\ ${ }^{1}$ Professor, ${ }^{2}$ Senior Lecturer, Dept. of Periodontics, ${ }^{1} \mathrm{JIS}$ University, Kolkata, ${ }^{2}$ Guru Nanak Institute of Dental Sciences \& \\ Research, Kolkata, West Bengal, India
}

*Corresponding Author:

Email: drgoutamgddc@gmail.com

\begin{abstract}
Rehabilitation of missing teeth by root form endosseus dental implants has revolutionized the treatment of partially and fully edentulous patients. Due to improved implant materials, armamentarium, and surgical techniques implants have got a very high success and survival rate. At the same time, the implants are associated with failures by peri-implant diseases due to various reasons related to improper diagnosis and treatment plan, and poor maintenance.
\end{abstract}

Keywords: Dental implant, Peri-implant mucositis, Peri-implantitis, Prevention.

\section{Introduction}

Man has tried to replace a mutilated tooth by a foreign material since long. Implant therapy has undoubtedly been a very successful alternative to restore functions in areas where teeth are missing. Though excellent long-term results are often presented, biological complications may occur in the form of soft tissue inflammation with or without bone loss around the implant, and pose a threat to long-term implant survival (Fig.1). ${ }^{1,2}$

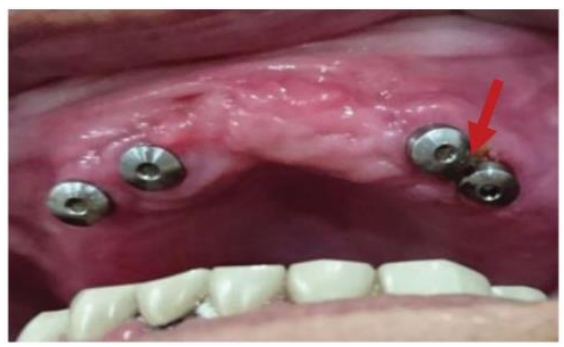

Fig. 1: Periimplant mucositis. Arrow indicates the area of involvement

The $6^{\text {th }}$ European Workshop in 2008 introduced a term peri-implant mucositis where gingival coronal tissues, ie, free-gingiva, and interdental gingiva, are first affected without involvement of alveolar bone. ${ }^{3}$ If not taken proper maintenance care at this stage of periimplant mucositis, this disease entity leads to periimplantitis with definite loss of alveolar bone and it is discernable through radiograph. Both of these two disease entities are the result of the imbalance of bacterial load and host defensive mechanism. ${ }^{4}$

\section{Definition}

The term peri-implantitis was introduced by Mombelli et al. (1992), who in a study on the microbiota at implants with and without bone loss concluded that "peri-implantitis can be regarded as a site specific infection which yields many features in common with chronic periodontitis". 5

At the first European Workshop on Periodontology, Peri-implant mucositis was defined as reversible inflammatory changes of the peri-implant soft tissues without any bone loss. Peri-implantitis was defined as an inflammatory process affecting the tissues around an osseointegrated implant in function, resulting in loss of supporting bone. ${ }^{6}$ Periimplantitis can be classified into early, moderate and advanced (Table 1). ${ }^{7}$

\section{Prevalence}

Koldsland et al. (2010) showed that the prevalence of periimplantitis ranged from 11 to $47 \%$ on 109 patients with implant treatment. ${ }^{8}$ According to Fransson et al. (2010), after the first year of function, there were bone losses of $\geq 2 \mathrm{~mm}(32 \%)$ and $\geq 3 \mathrm{~mm}(10 \%)$ around infected implant. The severity of periimplantitis associated with bone loss increases in proportion to the function time of the implant. ${ }^{9}$

\section{Normal periodontium and peri-implant mucosa}

The hard and soft tissues surrounding an osseointegrated implant show some similarities to the periodontium around natural dentition. The gingiva around dental implant is called peri-implant mucosa, and consists of well-keratinized oral epithelium, sulcular epithelium and junctional epithelium with underlying connective tissue.

Between the implant surface and epithelial cells are hemi-desmosomes and the basal lamina. Implants lack periodontal ligament. The collagen fibres are unattached and parallel to the implant surface rather than in functional contact from the bone to the cementum. The titanium screw attaches directly to the alveolar bone which is in direct and tight contact with the implant surface. The differences between dento-gingival and implant-gingival junction are shown in Table 2 . 
Table 1: Classification of peri-implantitis (Forum et al. 2012)

\begin{tabular}{|l|l|}
\hline Early & $\begin{array}{l}\mathrm{PD} \geq 4 \mathrm{~mm} \text { (bleeding and/or suppuration on probing) } \\
\text { Bone loss }<25 \% \text { of the implant length }\end{array}$ \\
\hline Moderate & $\begin{array}{l}\mathrm{PD} \geq 6 \mathrm{~mm} \text { (bleeding and/or suppuration on probing) } \\
\text { Bone loss } 25 \% \text { to 50\% of the implant length }\end{array}$ \\
\hline Advanced & $\begin{array}{l}\mathrm{PD} \geq 8 \mathrm{~mm} \text { (bleeding and/or suppuration on probing) } \\
\text { Bone loss }>50 \% \text { of the implant length }\end{array}$ \\
\hline
\end{tabular}

Table 2: The differencesbetween dento-gingival junction and implant-gingival junction

\begin{tabular}{|l|c|c|}
\hline & $\begin{array}{c}\text { Tooth -gingival } \\
\text { junction }\end{array}$ & $\begin{array}{c}\text { Implant -mucosal } \\
\text { junction }\end{array}$ \\
\hline Gingival fibers & $\begin{array}{c}\text { perpendicular to long } \\
\text { axis of tooth }\end{array}$ & parallel to long axis \\
\hline $\begin{array}{l}\text { fibroblast-fiber } \\
\text { ratio }\end{array}$ & $\begin{array}{c}\text { more fibroblasts } \\
\text { less collagen }\end{array}$ & Altered \\
\hline Vascularity & more & less \\
\hline biologic width & strong & Weak \\
\hline pd l & present & Absent \\
\hline tactile sensation & Present & Absent \\
\hline
\end{tabular}

\section{Etiopathogenesis}

Due to the reduced vascularisation and parallel orientation of the collagen fibres, peri-implant tissues are more susceptible for inflammatory disease than periodontal tissues. This phenomenon can be verified immunohistochemically through increased formation of inflammatory infiltrate, nitric oxide, lymphocytes, leukocytes.

An accumulation of microbes in plaque at the periimplant or mucosal margin causes a local inflammation, which is a complex reaction of the body in response to infectious agents. Inflammatory cells such as macrophages, neutrophils, lymphocytes and plasma cells, provoke considerable tissue damage.The degradation of connective tissue are followed by bone destruction, which marks the borderline between periimplant mucositis and peri-implantitis.

Two primary etiologic factors in peri-implant marginal bone loss:

1. Bacterial infection

2. Biomechanical overload

\section{Bacterial infection}

Healthy peri-implant sulcus is characterized by high proportions of cocci, a low ratio of anaerobic/aerobic species, a low number of gramnegative species and low detection frequencies for bacteria associated with periodontitis.

Quirynen et al. (2002) studied early microbial colonization of the "pristine" periimplant sulcus and reported that a complex microbiota was established within a week after abutment insertion ${ }^{10}$. Periimplantitis is a poly-microbial anaerobic infection which includes following micro-organisms: Prevotella intermedia, Prevotella nigrescens, Streptococcus constellatus, Aggregatibacter actinomycetemcomitans,
Porphyromonas gingivalis, Treponema denticola and Tannerella forsythia.

\section{Biomechanical Overload}

Bone loss at the coronal aspect of implants can result from biomechanical overloading and the resultant micro fractures at the coronal aspect of the implantbone interface. The loss of osseointegration in this region results in apical down growth of epithelium and connective tissue. The speed and degree of loss of implant-bone contact depends upon the frequency and magnitude of the occlusal loading as well as superimposed bacterial invasion. The role of over loading is likely to increase in four clinical situations:

1. Poor quality bone.

2. The implant's position

3. The patient has a pattern of heavy occlusal function associated with parafunction.

4. The prosthetic superstructure does not fit the implants precisely.

\section{Risk factors}

1. Smoking with additional significantly higher risk of complications in the presence of a positive combined IL-1 genotype polymorphism.

2. History of periodontitis.

3. Poor oral hygiene

4. Systemic diseases (e.g. diabetes mellitus, cardiovascular disease, immunosuppression.)

5. Iatrogenic causes (e.g. "cementitis").

6. Soft tissue defects or poor-quality soft tissue at the area of implantation (e.g. lack of keratinized gingiva).

7. History of failures of implants.

8. Alcohol consumption

9. Implant surfaces 


\section{Diabetes}

1. A study by Ferreira et al. (2006) showed that patients with diabetes (fasting blood sugar $\geq 126$ $\mathrm{mg} / \mathrm{dl}$ or had been taking anti-diabetic medicine over the past 2 week) were more prone than those without diabetes to develop peri-implantitis. ${ }^{11}$

2. The presence of periodontitis and diabetes were statistically associated with greater risk of periimplantitis.

3. The poor metabolic control in subjects with diabetes was associated with peri-implantitis.

\section{Alcohol consumption}

Only one study by Galindo-Moreno et al. (2015) concluded that peri-implant marginal bone loss was statistically linked to alcohol consumption $>10 \mathrm{gm}$. per day and that alcohol induced more serious periimplantitis than cigarette. Alcohol consumption is associated with deficiencies of the complement system, alteration of the neutrophil function and modulating Tlymphocyte activity, affects coagulation mechanisms, cause bone destruction and reduces bone formation. ${ }^{12}$

\section{Implant surfaces}

1. Most recent titanium implants with a rough surface showed more favourable osseointegration than those with smooth surfaces.

2. However, a rough surface also favoured the formation and retention of dental plaque.

3. Roughness increased both the adhesive surface of bacteria and the difficulty in cleaning the implant.

4. In a study by Astrand et al. (2004) ITI system dental implants (Straumann and Waldenburg, Switzerland) with a plasma-sprayed surface had a statistically higher incidence of peri-implantitis than Branemark system implants (Nobel Biocare , Gothenburg, Sweden) with a smooth surface. ${ }^{13}$

5. In a review by Renvert et al. (2011) there was no evidence that implant surface characteristics can have a significant effect on the initiation of periimplantitis. $^{14}$

\footnotetext{
Diagnosis

1. Bleeding on probing (Fig. 2 )

2. Peri-implant crevicular fluid

3. Microbial testing

4. Radiographic evaluation (Fig. 3a,3b)

5. Suppuration (Fig. 4)

6. Mobility
}

Peri-implantitis can be diagnosed by following features;

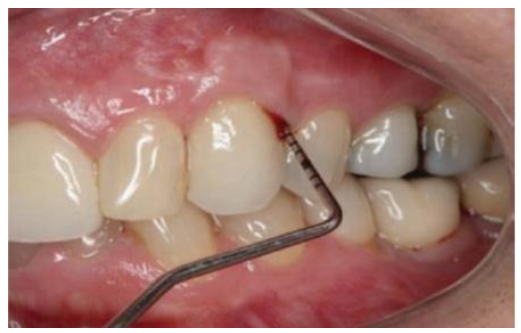

Courtesy: Renvert S, Polyzois I, Claffey N, J ClinPeriodontol. 2011;38(11):214-22

Fig. 2: Bleeding on probing.

\section{Peri-implant probing}

Standardized plastic probes should be recommended for peri-implant probing. Presence of bleeding on gentle probing $(0.25 \mathrm{~N})$ is a useful parameter for diagnosis of mucosal inflammation (Fig. 2). Experimental study showed that healthy periimplant sites had absence of BOP while there was increased BOP in mucositis (67\%) and peri-implantitis $(91 \%) .{ }^{15}$ Penetration of the probe up to $1.6 \mathrm{~mm}$. into the connective tissue occurred in the peri-implantitis lesion. ${ }^{16}$

\section{Peri-implant crevicular fluid (PICF) analysis}

Levels of biochemical mediators secreted into the PICF have been studied with the aim of identifying a diagnostic marker to monitor peri-implant health. Markers in PICF including cytokines such as IL-1ß, IL6, IL8, IL-17 and TNF $\alpha$, enzymes, and proteases have been investigated. ${ }^{17}$

\section{Microbial testing}

A microbiological test of sub-gingival microflora using a bacterial culture, checkerboard DNA-DNA hybridization, polymerase chain reaction (PCR), monoclonal antibody and enzyme assays could suggest antibiotic therapy.

\section{Radiographic evaluation}

Radiographic techniques including intra-oral peri apical radiography (IOPA) and panoramic tomography (OPG) (Fig. 3a, 3b) using long cone paralleling techniques have been widely used to monitor marginal bone levels at implants and to diagnose interproximal bone loss. Here the distance from a fixed reference point (e.g. implant shoulder or implant-abutment junction) to the inter-proximal bone level is recorded at baseline and monitored longitudinally. Multi-slice computer tomography (CT) and cone beam volume imaging have been used in implant dentistry offering the advantage that osseous structures can be represented in three planes, true to scale and without overlay or distortion. 

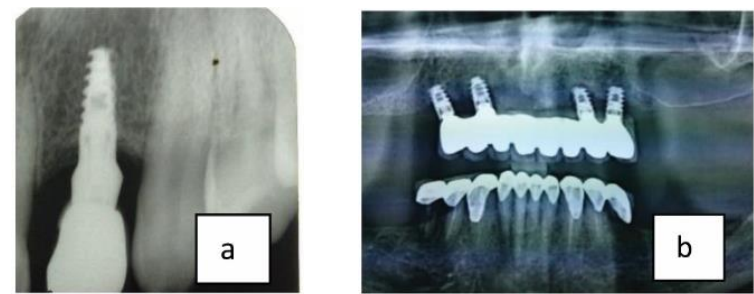

Fig. 3: Peri implant bone loss: a. IOPA radiograph; b: OPG

Experimental study in pig mandibles evaluated the accuracy and quality of the representation of prepared peri-implant defects by intraoral radiography, panoramic radiography, $\mathrm{CT}$ and cone beam radiography. Both $\mathrm{CT}$ and cone beam imaging techniques provided accurate three-dimensional representations of the peri-implant bone defects. The CT scans showed a slight artefact immediately adjacent to the implant while the cone beam scans showed the better imaging quality. ${ }^{18}$

\section{Suppuration}

Suppuration is one of the positive objective sign of periimplantitis (Fig. 4). ${ }^{19}$ In a report of 218 patients who were examined for biological complications at existing implants 9-14 years after implant placement, the presence of pus was identified as explanatory for periimplantitis resulting in apical level of bony defect at or apical to the third thread which is $\geq 3.1 \mathrm{~mm}$ apical to implant shoulder. ${ }^{20}$

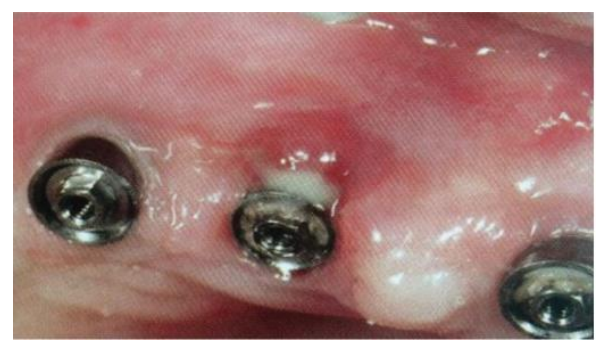

Courtesy: Renevert S, Giovannoli JL. Peri-Implantitis.: Quintessesnce

Fig. 4: Presence of Suppuration

\section{Mobility}

Mobility of an implant indicates complete lack of osseointegration and the implant should be removed. Mobility is therefore not useful for early diagnosis of peri-implant diseases.

\section{Treatment}

The indication for the appropriate treatment strategy has been demonstrated in patient studies leading to the development of the "cumulative interceptive supportive therapy (CIST)" concept. It was modified latter on and called AKUT-concept by Lang et al. (2004) (Table 3). ${ }^{21}$

The basis of this concept is a regular recall of the implanted patient and repeated assessment of plaque, bleeding, suppuration, pockets and radiological evidence of bone loss.

Table 3: AKUT concept

\begin{tabular}{|c|l|l|}
\hline Stage & \multicolumn{1}{|c|}{ Result } & \multicolumn{1}{|c|}{ Therapy } \\
\hline Normal & $\begin{array}{l}\text { Pocket dept (PD) <3 mm., no } \\
\text { plaque or bleeding }\end{array}$ & No therapy \\
\hline A & $\begin{array}{l}\text { PD <3 mm., plaque and/or } \\
\text { bleeding on probing }\end{array}$ & $\begin{array}{l}\text { Mechanically cleaning, polishing } \\
\text { oral hygiene instructions. }\end{array}$ \\
\hline B & $\begin{array}{l}\text { PD 4-5 mm., radiologically no } \\
\text { bone loss }\end{array}$ & $\begin{array}{l}\text { Mechanically cleaning, polishing, } \\
\text { oral hygienic instructions plus local } \\
\text { antiinfective therapy (e.g CHX). }\end{array}$ \\
\hline C & $\begin{array}{l}\text { PD }>5 \mathrm{~mm} ., \text { radiologically } \\
\text { bone loss }<2 \mathrm{~mm} .\end{array}$ & $\begin{array}{l}\text { Mechanically cleaning, polishing, } \\
\text { microbiological test, local and } \\
\text { systemic antiinfective therapy. }\end{array}$ \\
\hline D & $\begin{array}{l}\text { PD }>5 \mathrm{~mm} ., \text { radiologically } \\
\text { bone loss }>2 \mathrm{~mm} .\end{array}$ & Resective or regenerative surgery. \\
\hline
\end{tabular}

\section{Nonsurgical therapy}

1. Local debridement

2. Implant surface decontamination

3. Anti-infective therapy

4. Laser-assisted treatment of peri-implantitis

5. Photodynamic therapy

Surgical therapy

1. Resective surgery

2. Regenerative surgery

\section{Non surgical therapy \\ Local debridement}

The implant should be cleaned by instruments softer than titanium, such as polishing with a rubber cup and paste, floss, interdental brushes, or using plastic scaling instruments, teflon, carbon, plastic and titanium curettes (Figs. 5a,b). ${ }^{22}$

1. These have been shown not to roughen the implant surface unlike metal and ultrasonic scalers. 
2. Karring et al. (2015) demonstrated that submucosal debridement alone, using either with an ultrasonic device or carbon fiber curettes, is not sufficient for the decontamination of the surfaces of implants with peri-implant pockets $\geq 5 \mathrm{~mm}$ and exposed implant threads. ${ }^{23}$

3. So it has been suggested that mechanical or ultrasonic debridement alone may not be an adequate modality for the resolution of periimplantitis.

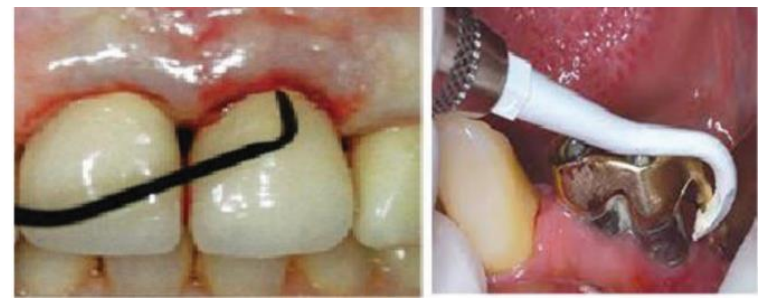

Courtesy: Vandana KL, Dalvi P, Nagpal D. Treatment of periimplant diseases. J IntClin dent Res Organ. 2015;1(7):160-79

Fig. 5: Local debridement: a) Carbon fiber curettes; b) Plastic scaler

\section{Implant surface decontamination}

1. There are several methods for implant surface decontamination, such as citric acid, photosensitizing treatment, stannous fluoride, tetracycline- $\mathrm{HCl}$, chlorhexidine gluconate, hydrogen peroxide, sterile water, a plastic sonic scaler tip and an air powder abrasive unit.

2. An abrasive air polishing medium can modify the surface of implants.

3. After air powder treatment cell attachment and cell viability still showed sufficient levels, but cell response was decreased compared with sterile surfaces.

\section{Anti-infective therapy}

1. Antiseptic rinses in relation to different parameters.

2. Application of systemic and locally delivered antibiotics in relation to pocket depth or different parameters.

3. Schwarz et al. (2006) demonstrated that the treatment of peri-implant infection by mechanical debridement with plastic curettes combined with antiseptic ( $0.2 \%$ chlorhexidine) therapy may lead to statistically significant improvements in bleeding on probing, peri-implant probing pocket depth, and clinical attachment level at 6 months compared with baseline. ${ }^{24}$

4. Renvert et al. (2008) showed that combined mechanical treatment with a repeated local application of minocycline microspheres (Arestin, OraPharma, Warminster, PA, USA) after 30 and 90 days and showed benefits in the therapy of periimplantitis. This study also indicated that mechanical treatment combined with the local application of an antibiotic achieved a better result, but in addition of antiseptic therapy to mechanical debridement does not provide adjunctive benefits in shallow peri-implant lesions where the mean probing pocket depth was $<4 \mathrm{~mm} .^{25}$

5. Astasov-Frauenhoffer et al. (2014) found complete growth-inhibiting effects of amoxicillin and metronidazole on Streptococcus sanguinis, Porphyromonas gingivalis and Fusobacterum nucleatum apart from each other, but the combination was found to be more efficient than metronidazole alone. ${ }^{26}$

\section{Laser-assisted treatment of peri-implantitis}

1. A study by Schwarz et al. (2006) on the efficiency of the ErYAG laser showed the improvement of bleeding on probing was greater in laser treatment than that of using a mechanical treatment (plastic curettes) combined with an antiseptic agent $(0.2 \%$ chlorhexidine digluconate) in the non-surgical therapy of peri-implantitis. ${ }^{27}$

2. Sajjad et al. (2014) proposed different laser systems with bactericidal effects, tissue ablation and detoxification for the therapy of periimplantitis. Erbium-doped yttrium, aluminum and garnet (ErYAG) laser has the ability to remove dental plaque and calculus on the smooth or porous surface of implants without causing alterations. The ErYAG laser also showed reduction of the peri-implant pocket and attachment gain after 6 months. ${ }^{28}$

\section{Photodynamic therapy}

1. Bombeccari et al. (2013) stated in a study after manual debridement by titanium curettes and glycerine air powder treatment, half of the patients received adjunctive photodynamic therapy and the other half received minocycline microspheres into implant pockets. After 12 months, the number of periopathogenic bacteria and level of IL-1 $\beta$ decreased significantly in both groups without significant differences between them. ${ }^{29}$

2. Deppe et al. (2013) stated that photodynamic therapy generates reactive oxygen species by multiplicity with help of a high-energy singlefrequency light (e.g. diode lasers) in combination with photosensitizers (e.g. toluidine blue).In a wave length range of 580 to $1400 \mathrm{~nm}$. and toluidine blue-concentrations between 10 and 50 $\mu \mathrm{g} / \mathrm{ml}$, photodynamic therapy generates bactericidal effects against aerobic and anaerobic bacteria (Aa, P. gingivalis, P. intermedia, Streptococcus mutans, Enterococcus faecalis). ${ }^{30}$

\section{Surgical therapy}

1. The surgical therapy combines the concepts of the already mentioned non-surgical therapy with those of resective and/or regenerative procedures.

2. Classification of the morphology of peri-implant lesions was important for choosing a reliable type 
of bone regeneration and for prognosis of surgical therapy of periimplantitis.

A predictable bone growth in human around failing implant was demonstrated for the first time by Fletcher et al. (2018). ${ }^{31}$

\section{Classification of peri-implant bone defects} (Schwarz et al. 2007) $)^{32}$

A. Class I consisted of infrabony destruction.

B. Class II characterized by horizontal bone loss.

Class I subdivided into:

1. Class la (buccal dehiscence)

2. Class $\mathrm{lb}$ (buccal dehiscence + semicircular bone resorption to the middle of the implant body)

3. Class Ic (buccal dehiscence + circular bone resorption under maintenance of the lingual compacta)

4. Class Id (buccal dehiscence + circular bone resorption under loss of the lingual compacta)

5. Class Ie (circular bone resorption under maintenance of the buccal and oral compacta).

The bone defects most frequently found in periimplantitis are class le $(55.3 \%)>$ class $\mathrm{lb}(15.8 \%)>$ class Ic $(13.3 \%)$, >class Id $(10.2 \%)>$ class la $(5.4 \%)$.

The application of bone regeneration seems to be more favourable in class I bone destruction, but it is very limited in class II defects.

The best results for reducing pocket and clinical attachment gain are found in class le defects.

\section{Resective therapy}

1. Peri-implantitis with suprabony destruction, onewall infrabony defects or buccal dehiscences in non-esthetic regions, the resective surgery including osteotomy or osteoplasty associated with the polishing of the transmucosal implant part and apically positioned flap has been suggested.

2. The goals of resective surgery are the reduction of the peri-implant pocket and the morphological reconstruction of soft tissue to promote patients' oral-implant hygiene.

3. A clinical study by Romeo et al. (2005) demonstrated that resective therapy associated with implantoplasty improved the survival of infected implants. ${ }^{33}$

4. Implantoplasty is also a form of surface decontamination as it involves eliminating the implant threads to achieve a smooth polished surface to decontaminate and reduce the ability of plaque to adhere to the implant surface, but four concerns exist:

i. Heat production

ii. Deposit of implant material into the surgical field

iii. Damage to the implant surface

iv. Weakening of the implant structure.

Heat production is easily managed by effective irrigation and appropriate bur selection.
In a dog study, titanium debris from implantoplasty produced a histological inflammatory cell infiltrate in adjacent tissue but the debris was very minor, undetectable via computed tomography by Schwartz et al. (2011).It has been suggested that these depositions are not associated with any adverse events clinically. ${ }^{34}$

\section{Regenerative therapy}

1. Resective surgical therapy may result in reosseointegration in only minor superficial defects. From functional, aesthetic and long-time-survival point of views, full regeneration and reosseointegration is aspired (Fig. 6).

2. A study of autogenous bone graft by Behneke et al.(2000) on 17 patients with 25 treated implants showed a reduction of the peri-implant pocket from 6.9 to $0.7 \mathrm{~mm}(\mathrm{P}=0.001)$, corresponding to $90 \%$ bone reconstruction and Median marginal bone loss was reduced from 6.2 to $2.3 \mathrm{~mm}$ after 2 and 3 years, respectively. The median vertical bone resorption of $4.5 \mathrm{~mm}$ was completely repaired. ${ }^{35}$

3. The application of a membrane barrier gave protection from blood clots and created a space around peri-implant defects to promote bone regeneration as well as to avoid competition from other tissues.

4. Collagen membranes were recommended for their convenient properties like hemostatic function, early stabilization, chemotactic activity attracting fibroblasts and semi-permeability.

5. In a recent prospective case series by Matarasso et al.(2014), a combined resective and regenerative approach including a bovine bone mineral and a collagen membrane infracrestally and implantoplasty supracrestally showed a significant peri-implant probing depth reduction and an increased radiographic defect fill after 12 months of follow-up. ${ }^{36}$

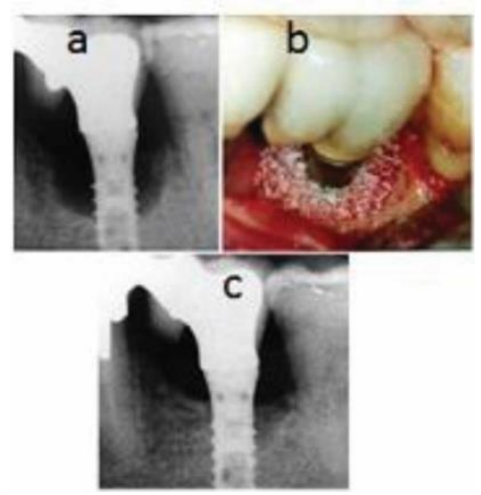

Courtesy: Renevert S, Giovannoli JL. Peri-Implantitis: Quintessesnce International. France, 2012; 161

Fig. 6: Surgical Correction: a. Pre-operative radiograph; b. Placement of bone graft material; $c$. Post-operative follow-up radiograph

Laser-assisted surgical treatment of peri-implantitis 
The contamination of the implant surface limited the success of this bone regeneration procedure. The efficiency of bacterial reduction by lasers has been confirmed by several studies. The effect of coagulation by laser permitting good stabilization of blood clots and good contact of substitutive materials with the implant surface promoted re-osteointegration. The clinical cases reported by Haas et al. in 2000 using combined methods (curettage + laser assisted decontamination of implant surfaces + autogenous bone graft + ePTFE membrane + systemic antibiotic therapy for 5 days) showed great results for peri-implantitis treatment with a $36.4 \%$ bone gain after 10 months. ${ }^{37-40}$

\section{The new classification of peri-implant diseases and conditions $^{41}$}

A new classification scheme for peri-implant diseases and conditions has been recently suggested in World Workshop held at Chicago on November 9 to 11, 2017 under the aegis of American Academy of Periodontology (AAP) and European Federation of Periodontology (EFP). This is published in Journal of Clinical Periodontology in its March issue of 2018 as a supplement by ten authors. It is stated that there are four terminologies to be used for designating different varieties of status for peri-implant diseases and conditions around an implant. These are: peri-implant health, peri-implant mucosities, peri-implantitis, and peri-implant hard and soft tissue deficiencies.

\section{Conclusion}

Prognosis of the affected implant will be contingent upon early detection and treatment of periimplant mucositis and peri-implantitis. Differentiating peri-implantitis with and without pus formation is an important criterion that influences the outcome of nonsurgical and surgical therapy.

\section{References}

1. Pal TK. Fundamentals and history of implant dentistry. J Int Clin Dent Res Organ. 2015; 7(1):6-12.

2. AAP proceedings. Peri-implant mucositis and periimpantitis: A current understanding of their diagnosis and clinical implications. J Periodontol. 2013;84(4):436-9.

3. Lindhe J, Meyle J. Peri-implant diseases: Consensus Report of the Sixth European Workshop on Periodontology. J Clin Periodontol. 2008;35(8):282-5.

4. Turner PS, Vazifdar FT, Turner AP, Vazifdar DR. Clinical guide to oral implantology step by step procedures. $3^{\text {rd }}$ ed. New Delhi: Jaypee Brothers Medical Publishers (P) Ltd; 2018.

5. Mombelli A, Lang NP. Antimicrobial treatment of periimplant infections. Clin Oral Implants Res. 1992;3:162-8.

6. Lang NP, Karring T. Proceedings of the 1st European Workshop on Periodontics, 1993. London: Quintessence; 1994; 120-126

7. Froum SJ Rosen PS. A proposed classification for periimplantitis. Int J Periodontics Restorative Dent. 2012;32(5):533-40.

8. Koldsland OC, Scheie AA, Aass AM Prevalence of PeriImplantitis, related to severity of the disease with different degrees of bone Loss. J Periodontol 2010;81(2):231-7.

9. Fransson C, Tomasi C, Pikner SS, Gröndahl K, Wennström JL, Leyland AH. Severity and pattern of periimplantitis-associated bone loss. J Clin Periodontol. 2010;37:442-8.

10. Quirynen M, De Soete M, van Steenberghe D. Infectious risks for oral implants: a review of the literature. Clin. Oral Implants Res. 2002;13(1):1-19.

11. Ferreira SD, Silva GL, Cortelli JR, Costa JE, Costa FO. Prevalence and risk variables for peri-implant disease in Brazilian subjects. J Clin Periodontol. 2006;33(12):92935.

12. Galindo-Moreno P, Leon-Cano A, Ortega-Oller I, Monje A, Catena A. Marginal bone loss as success criterion in implant dentistry: beyond $2 \mathrm{~mm}$. Clin Oral Impl Res. 2015;26(4):28-34

13. Astrand P, Engquist B, Dahlgren S, Grondahl K, Engquist E, Feldmann H. Astra Tech and Branemark system implants: A 5-year prospective study of marginal bone reactions. Clin Oral Implants Res. 2004;15(4):413-20.

14. Renvert S, Polyzois I, Claffey N. How do implant surface characteristics influence peri-implant disease. J Clin Periodontol. 2011; 38(11):214-22.

15. Jepsen S, Rühling A, Jepsen K, Ohlenbusch B, Albers HK. Progressive periimplantitis. Incidence and prediction of periimplant attachment loss. Clin Oral Implants Res. 1996;7:133-42.

16. Lang NP, Wetzel AC, Stich H, Caffesse RG. Histologic probe penetration in healthy and inflamed peri-implant tissues. Clin Oral Implants Res. 1994;5(4):191-201.

17. Javed F, Al-Hezaimi K, Salameh Z, Almas K, Romanos GE. Proinflammatory cytokines in the crevicular fluid of patients with peri-implantitis. Cytokine. 2011;(53):8-12.

18. Kullman L, Asfour AA, Zetterqvist L, Andersson L. Comparison of radiographic bone height assessments in panoramic and intraoral radiographs of implant patients. Int J Oral Maxillofac Implants. 2007;22(1):96-100.

19. Renevert S, Giovannoli JL. Peri-Implantitis.France: Quintessesnce International.2012;21.

20. Roos-Jansaker AM, Lindahl C, Renvert H, Renvert S. Nine-to fourteen-year follow-up of implant treatment. Part II: presence of peri-implant lesions. J Clin Periodontol. 2006;33(4):290-5.

21. Lang NP, Berglundh T, Heitz-Mayfield LJ, Pjetursson BE, Salvi GE, Sanz M. Consensus statements and recommended clinical procedures regarding implant survival and complications. Int J Oral Maxillofac Implants. 2004;19:150-4.

22. Vandana KL, Dalvi P, Nagpal D. Treatment of periimplant diseases. J Int Clin Dent Res Organ. 2015;1(7):160 -79.

23. Karring ES, Stavropoulos A, Ellegaard B, Karring T. Treatment of peri-implantitis by the Vector system. Clin Oral Implants Res 2015;16(3):288-93.

24. Schwarz F, Bieling K, Bonsmann M, Latz T, Becker J. Nonsurgical treatment of moderate and advanced periimplantitis lesions: a controlled clinical study. Clin Oral Invest. 2006;10(4):279-88.

25. Renvert S, Roos-Jansaker AM, Claffey N. Non-surgical treatment of peri-implant mucositis and peri-implantitis: a literature review. J Clin Periodontol. 2008;35(8):305-15.

26. Astasov-Frauenhoffer M, Braissant O, Hauser-Gerspach I, Weiger R, Walter C, Zitzmann NU, Waltimo T. Microcalorimetric determination of the effects of amoxicillin, metronidazole, and their combination on in vitro biofilm. J Periodontol. 2014;85(2):349-57. 
27. Schwarz F, Nuesry E, Bieling K, Herten M, Becker J. Influence of an erbium, chromium-doped yttrium, scandium, gallium, and garnet (Er, Cr: YSGG) laser on the reestablishment of the biocompatibility of contaminated titanium implant surfaces. J Periodontol. 2006;77(11):1820-27.

28. Ashnagar S, Nowzari H, Nokhbatolfoghahaei H, Zadeh BY, Chiniforush N, Zadeh NC. Laser treatment of periimplantitis: a literature review. J Lasers Med Sci. 2014;5(4):153.

29. Bombeccari GP, Guzzi G, Gualini F, Gualini S, Santoro F, Spadari F. Photodynamic therapy to treat periimplantitis. Implant Dent. 2013;22(6):631-8.

30. Deppe H, Mucke T, Wagenpfeil, Sculean A. Nonsurgical antimicrobial photodynamic therapy in moderate $v s$ severe peri-implant defects: a clinical pilot study. Quintessence Int. 2013;10:1-10.

31. Fletcher P, Deluiz D, Tinoco EM, Ricci JL, Tarnow DP, and Tinoco JM. Human Histologic evidence of Reosseointegration around an Implant affected with periimplantitis following decontamination with sterile saline and antiseptics: A case history report. Quintessence India, $2018 ; 2(1): 11-22$.

32. Schwarz F, Herten M, Sager M, Bieling K, Sculean A, Becker J. Comparison of naturally occurring and ligature-induced peri-implantitis bone defects in humans and dogs. Clin Oral Implants Res. 2007; 18: 161-70.

33. Romeo E, Ghisolfi M, Murgolo N, Chiapasco M, Lops D, Vogel G. Therapy of peri-implantitis with resective surgery. Clin Oral Implants Res. 2005;16(1):9-18.

34. Schwarz F, Sahm N, Mihatovic I, Golubovic V, Becker J. Surgical therapy of advanced ligature-induced peri-implantitis defects: cone-beam computed tomographic and histological analysis. J Clin Periodontol. 2011;38(10):939-49.

35. Behneke A, Behneke N, d'Hoedt B. Treatment of periimplantitis defects with autogenous bone grafts: sixmonth to 3-year results of a prospective study in 17 patients. Int J Oral Maxillofac. 2000;15(1):125-38.

36. Matarasso S, Siciliano VI, Aglietta M, Andreuccetti G, Salvi GE. Clinical and radiographic outcomes of a combined resective and regenerative approach in the treatment of peri-implantitis: a prospective case series. Clin Oral Implants Res. 2014;25(7):761-7.

37. Das G, Banerjee S, Chakrabortry A, Pal TK. Periimplantitis and its management: a current status. JIDA. 2016;10(2);29-34.

38. Persson LG, Mouhyi J, Berglundh T, Sennerby L, Lindhe J. Carbon dioxide laser and hydrogen peroxide conditioning in the treatment of periimplantitis: an experimental study in the dog. Clin Implant Dent Relat Res. 2004;6(4):230-8.

39. Ashnagar S, Nowzari H, Nokhbatolfoghahaei H, Zadeh BY, Chiniforush N, Zadeh NC. Laser treatment of periimplantitis: a literature review. J Lasers Med Sci. 2014;5(4):153-62

40. Kurtzman GM, Weitz M, Kaminer R, Gober DD. Treatment of peri-implantitis with the picasso diode laser: A long-term follow-up after debridement and grafting. Inside dentistry. 2016:1-5.

41. Jack G. Caton, Garry Armitage, Tord Berglundh, Iain L.C. Chapple, SØren Jepsen, Kenneth S. Kornman, Brian L. Mealey, Panos N. Papapanou, Mariano Sanz, Maurizio S. Tonetti. A new classification scheme for periodontal and peri-implant diseases and conditions - Introduction and key changes from the 1999 classification. J Clin Periodontol. 2018; 45:45 (supple 20): S1-S8. 